\title{
Respiratory Response to Electrical Stimulation of the Brain Stem of Fetal and Neonatal Sheep
}

\author{
V. Ghernick ${ }^{[18]}$, V. Havlicek, R. D. Pagtakhan, and A. Sklenovsky \\ Perinatal Physiology Laboratory, Departments of Physiology and Pediatrics, University of Manitoba, Faculty of Medicine, and \\ Children's Hospital of Winnipeg, Winnipeg, Manitoba, Canada
}

\begin{abstract}
Extract
Focal electrical stimulation of the medulla was undertaken in exteriorized fetal sheep and neonatal lambs, anesthetized with pentobarbital. The area from which respiratory responses were obtained was mapped using stereotaxic coordinates. Focal stimulation of the fetal medulla caused one or two inspiratory gasps. In only a few instances was the response expiratory and this appeared to be nonspecific. The area in the fetal brain stem from which respiratory responses were elicited was diffuse and extended from obex to lower pons. This region occupied a volume of about $130 \mathrm{~mm}^{3}$.

In one exteriorized fetus with spontaneous, rhythmic ventilation, focal stimulation caused an apneic pause. Later when respiration ceased spontaneously, focal stimulation at the same current strength induced inspiratory gasps. In the spontaneously breathing neonatal lamb, focal stimulation of the medulla was associated with a diminution in tidal volume and an apneic pause could be produced with an increase in current strength. The apneic pause occurred at about the same current strength as that required to initiate respiration in the fetus.

In the neonatal lamb the brain stem area from which a respiratory response could be obtained was less diffuse than that of the fetus and occupied a volume of about $65 \mathrm{~mm}^{3}$. This region was similar to the inspiratory center of adult sheep reported by others.
\end{abstract}

\section{Speculation}

The respiratory center of the fetus appears to be just as sensitive to focal electrical stimulation as that of the neonatal animal. However, differing ventilatory response to stimulation depending on the presence or absence of respiration suggests a different functional organization of the fetal respiratory center. This is further supported by the characteristic inspiratory response of the fetus and the diffuse area from which such a response was obtained.

\section{Introduction}

Rhythmic respiration, absent in utero, must begin within moments after birth in order to sustain life. The medullary respiratory structures of the fetus therefore must be well developed near term in order for this transition to be accomplished rapidly. The absence of respiration in utero is difficult to explain since fetal arterial blood $\mathrm{P}_{\mathrm{O}_{2}}$ is about $25-30 \mathrm{~mm} \mathrm{Hg}$, levels which would result in a marked respiratory response in the adult. On the basis of indirect studies in fetal sheep, Barcroft [3] suggested that there was active inhibition of the respiratory center near term. Burns 
and Salmoiraghi [4] have suggested, on the basis of data obtained by study of adult cats, that fetal respiratory neurones may be quiescent because of a lack of neuronal traffic through the medullary reticular formation. However, there have been no direct studies of the fetal respiratory center of the fetal lamb. The present report is therefore concerned with the anatomical localization of the medullary respiratory structures as determined by focal electrical stimulation in near-term fetal sheep and neonatal lambs.

\section{Methods}

Pregnant ewes near term (142-147 days) were anesthetized with intravenous pentobarbital, $20 \mathrm{mg} / \mathrm{kg}$. Additional pentobarbital (in doses of $3 \mathrm{mg} / \mathrm{kg}$ ) was administered intravenously as required, usually every 35-60 $\mathrm{min}$. The ewe was placed in the right lateral decubitus position and the fetus exteriorized through caesarian section. The umbilical cord was left intact and covered with gauze soaked in warmed saline. Fetal rectal temperature was maintained between 38.5 and $40^{\circ}$ by means of a heating blanket. The head of the fetus was placed in a stereotaxic head holder which had been designed specifically to allow for maintenance of the head in the central position by metal holders at the suborbital regions, external auditory canals, and hard palate. Xylocaine, 1\%, was infiltrated at local contact points. The head was maintained in a flexed position so that a plane between the external auditory meatus and the lowest point on the inferior orbital margin was at $25^{\circ}$ below the horizontal plane. Preliminary experiments indicated that with the head in this position the stimulating electrode was perpendicular to the floor of the fourth ventricle. In this position, the tentorium cerebelli was displaced in a rostral direction so that the stimulating electrode could be introduced to the pontine level of the brain stem without perforating the tentorium. An occipital craniotomy was done removing an approximately $2.5-\mathrm{cm}$ diameter portion of the occipital bone just posterior to the lambda in the midline. The dura was left intact. Bleeding was controlled with Gelfoam soaked in fibrin and topical thrombin. All stereotaxic coordinates were related to coronal and horizontal planes through the external auditory canals ("zero" planes).

At the end of each experiment $50 \mathrm{ml}$ saline followed by $50 \mathrm{ml} 10 \%$ formalin was perfused through each carotid artery. The animal was then decapitated and the head placed in 10\% formalin for 2-3 weeks. After tixation of the nerve tissue electrode placements were checked by macroscopic measurements and histologic examination of each brain stem in the following manner. The head was fixed in the stereotaxic apparatus, the cerebellum removed, and in each animal the relation between anatomic landmarks of the medulla and the zero planes was measured. A part of the brain stem extending from $3 \mathrm{~mm}$ below the obex to a point in the lower pons, about $14 \mathrm{~mm}$ above the obex, was removed for histologic examination with silver and Nissl stains. There was no macroscopic hemorrhage into the brain stem although, occasionally, minimal hemorrhage was noted on examination of the histologic sections.

Stimulation of the brain stem was done with a Grass S8 [12] stimulator in combination with a constant current unit isolated from the stimulator by an isolation unit. Trains of square wave pulses were used with a frequency of $250 \mathrm{~Hz}$ and a duration of $0.5 \mathrm{msec}$. Each site was stimulated for a period of $10 \mathrm{sec} ; 15 \mathrm{sec}$ were allowed for recovery. The initial stimulating current at each placement of $0.10 \mathrm{ma}$ was increased in approximately $0.15 \mathrm{ma}$ increments until either a respiratory response was obtained or a maximum of $1.5 \mathrm{ma}$ was reached. Stimulating electrodes were bipolar and of either stainless steel (two fetuses) or platinum (four fetus and four neonatal lambs). The bipolar electrodes were insulated with resin and each tip had a diameter of $0.24 \mathrm{~mm}$ with an interelectrode distance of $0.15 \mathrm{~mm}$.

For the purposes of mapping, up to 14 electrode placements were made in each animal. At two or three placements near the midline, the thickness of the medulla was estimated by inserting the electrode until it hit the basioccipital bone and then withdrawing dorsally in 2-mm steps. Once the depth was known further placements were made in a dorsal-ventral direction thus avoiding any possible injury effect. Although this procedure was followed, the results were seen to be independent of the direction of movement of the electrode. After stimulation at each position, the electrode was moved ventrally in 2-mm increments so that four stimulations were carried out at each placement. In this manner 350 different sites were stimulated in the six fetuses. The minimal current required to achieve a respiratory response at each site was defined as the threshold current.

The fetal trachea was cannulated and connected to a volume plethysmograph consisting of a 30-liter capacity bottle containing 2-3 liters saline. Any respiratory effort thus resulted in liquid breathing by the fetus. Changes in pressure within the plethysmograph were recorded [13]. Volume was calibrated at a frequency of 
5-10 cpm with a syringe attached to the plethysmograph. A fetal femoral artery was also cannulated for sampling of blood for blood gas and $\mathrm{pH}$ determination.

Four neonatal lambs, 3-5 days of age, were anesthetized with pentobarbital, $10 \mathrm{mg} / \mathrm{kg}$ intraperitoneally. In contrast to the ewes, the neonates did not, as a rule, require supplemental doses of pentobarbital during the experiment. A tracheostomy was performed and respiration monitored by a pneumotachograph and differential pressure transducer, the signal from which was amplified by a recorder [13] and integrated to display inspired tidal volume. This method did not

Table I. Relationship between external stereotaxic coordinates and anatomic landmarks in fetal sheep and neonatal lambs ${ }^{I}$

\begin{tabular}{lcc}
\hline & Fetus, mm & Neonate, mm \\
\hline $\begin{array}{l}\text { Distance from lambda to } \\
\text { coronal zero plane }\end{array}$ & $5.60 \pm 0.77$ & $5.10 \pm 1.08$ \\
$\begin{array}{c}\text { Distance from obex to } \\
\text { coronal zero plane }\end{array}$ & $11.08 \pm 0.19$ & $12.05 \pm 0.38$ \\
$\begin{array}{c}\text { Distance from zero hori- } \\
\text { zontal plane to the sur- }\end{array}$ & $-1.54 \pm 0.15$ & $-1.93 \pm 0.20$ \\
face of IV ventricle & $(11)$ & $(6)$ \\
Thickness of medulla ob- & $6.56 \pm 0.19$ & $7.10 \pm 0.21$ \\
$\quad \begin{array}{l}\text { longata in midline } 2 \\
\text { mm rostral to obex }\end{array}$ & $(6)$ & $(4)$ \\
Thickness of medulla ob- & $8.30 \pm 0.50$ & $8.97 \pm 0.16$ \\
longata (2 mm rostral & $(5)$ & $(4)$ \\
to obex and 3 mm & & \\
lateral to midline) & & \\
\hline
\end{tabular}

${ }^{1}$ Values represent means \pm sE. Number of samples appears in parentheses.

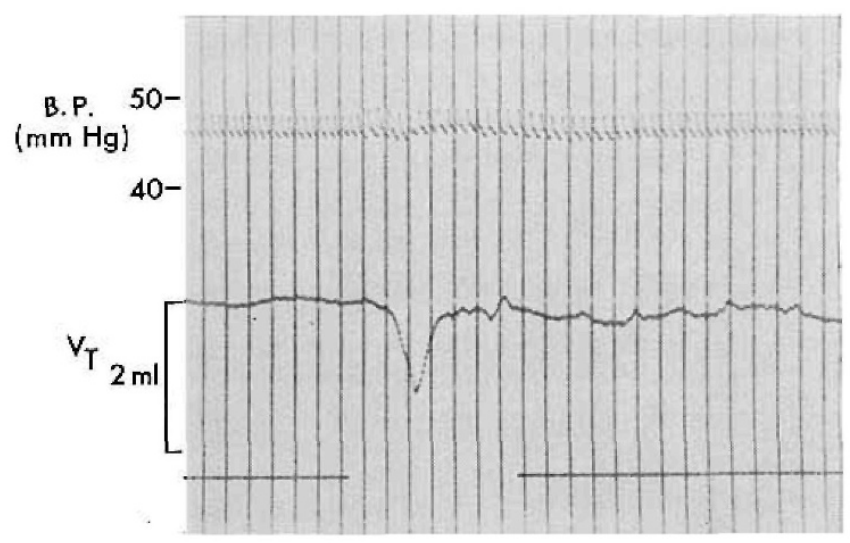

Fig. 1. Recording taken during fetal lamb experiment indicating (top to bottom) femoral blood pressure (B.P.), respiration, and baseline channel. Break in base-line indicates onset of stimulating current. Note slight slowing of heart rate with no change in blood pressure and single inspiratory gasp. Time lines indicate seconds. allow the monitoring of midpositional shifts in lung volume but did yield information regarding apnea or changes in tidal volume. Electrode placements in the neonatal lambs were carried out as described for the fetal sheep and a total of 282 sites were stimulated in the four neonatal lambs. Intermittent blood samples were obtained for blood gas and $\mathrm{pH}$ determination from a cannulated femoral artery.

Fetal and neonatal femoral arterial blood $\mathrm{pH}, \mathrm{P}_{\mathrm{CO}_{2}}$, and $\mathrm{P}_{\mathrm{O}_{2}}$ were determined with a Radiometer $\mathrm{pH}$ meter and microelectrodes at a temperature within $0.5^{\circ}$ of the rectal temperature of the animals.

\section{Results}

The distances from the horizontal and coronal zero planes and various anatomic landmarks are shown in Table I. The distances between the coronal zero plane and the fetal lambda and obex were quite constant and averaged $5.60 \pm 0.77$ and $11.08 \pm 0.19 \mathrm{~mm}$, respectively. The distance from the lambda to the obex averaged about $5.5 \mathrm{~mm}$. The surface of the fourth ventricle was about $1.5 \mathrm{~mm}$ above the zero horizontal plane. The distances from the obex to the coronal zero plane were slightly greater in the neonatal lambs and there was slightly greater variation in the distance from lambda to the coronal zero plane. Measurements of the thickness of the medulla are also shown in Table I and these indicate that the medulla of the neonate is slightly thicker than that in the fetal sheep near term.

Stimulation of the fetal brain stem resulted in one or two inspiratory gasps which varied in tidal volume from 3-6 $\mathrm{ml}$ (Fig. I). A deep expiratory response was never seen. Respiration ceased when the stimulating current was withdrawn. Fetal femoral arterial blood gases remained similar to control levels during and after the stimulation although there was a gradual development of an acidosis with increasing length of time following exteriorization. There was no correlation between fetal arterial blood gases and $\mathrm{pH}$ and the threshold current required to induce a respiratory response.

The localization of the areas of response are shown in coronal sections through the brain stem in Figure 2 and the horizontal projection onto the dorsal surface of the medulla in Figure 3. Respiratory responses were obtained from an area extending from the obex to the lower pons and laterally for about $2-3 \mathrm{~mm}$ on either side of the midline. The lowest thresholds for a response were usually obtained in an area about $6 \mathrm{~mm}$ (from 3-9 $\mathrm{mm}$ ) rostral to the obex in the ventral por- 

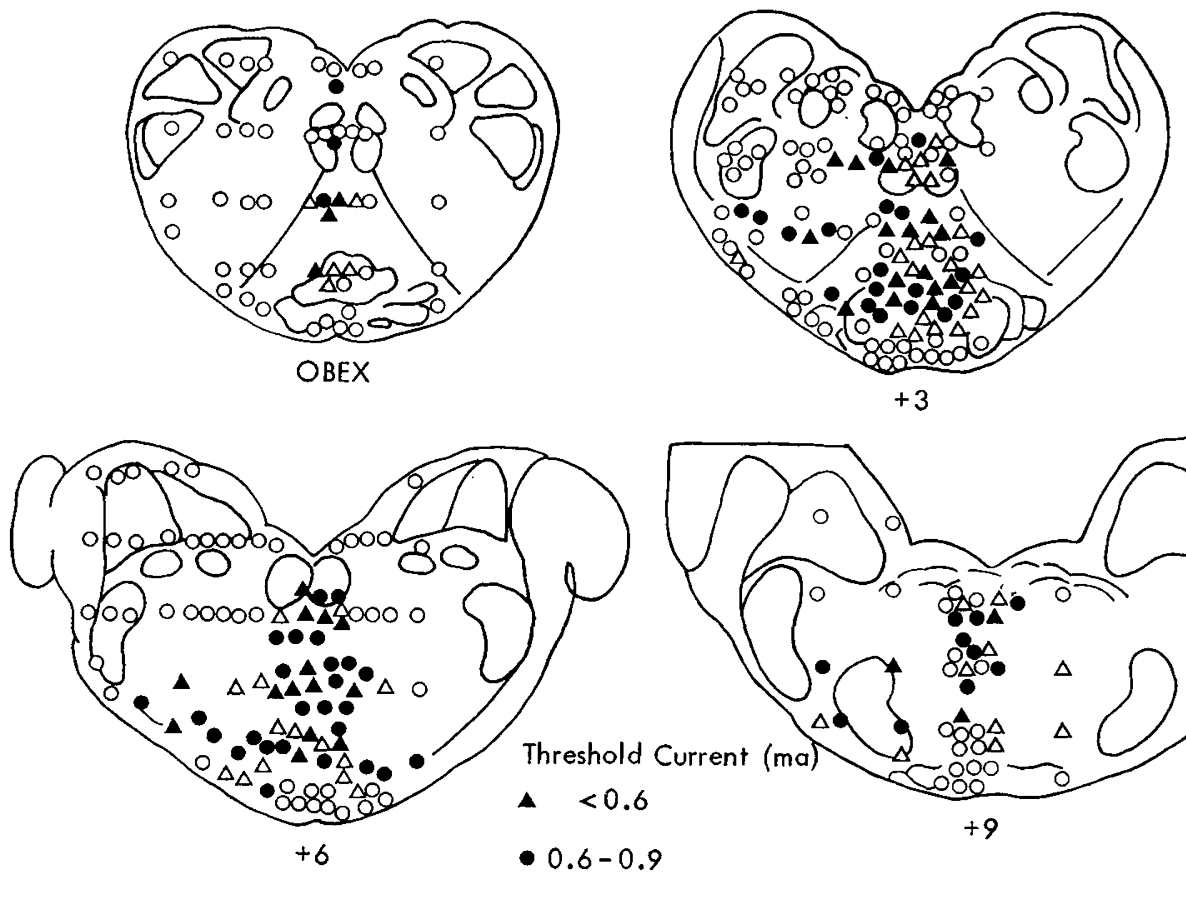

$\Delta 1.0-1.4$

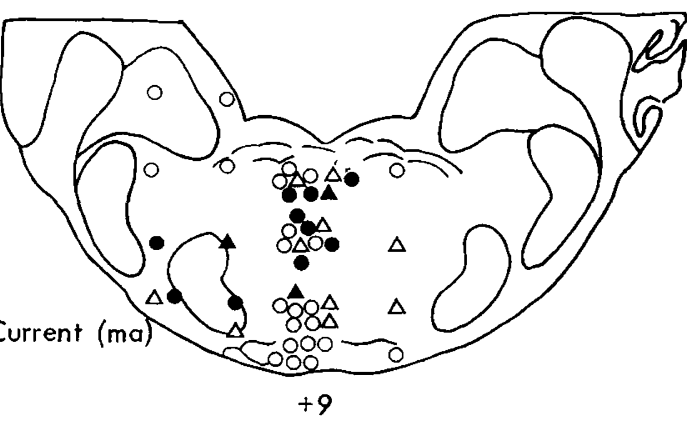

O NO RESPONSE TO 1.5

Fig. 2. Representative coronal sections of the brain stem of term fetal sheep at the level of the obex and 3,6, and $9 \mathrm{~mm}$ rostral to the obex. The sites stimulated, regions from which ventilatory responses were obtained, and the threshold currents are indicated by the various symbols. — $4 \mathrm{~mm}$.

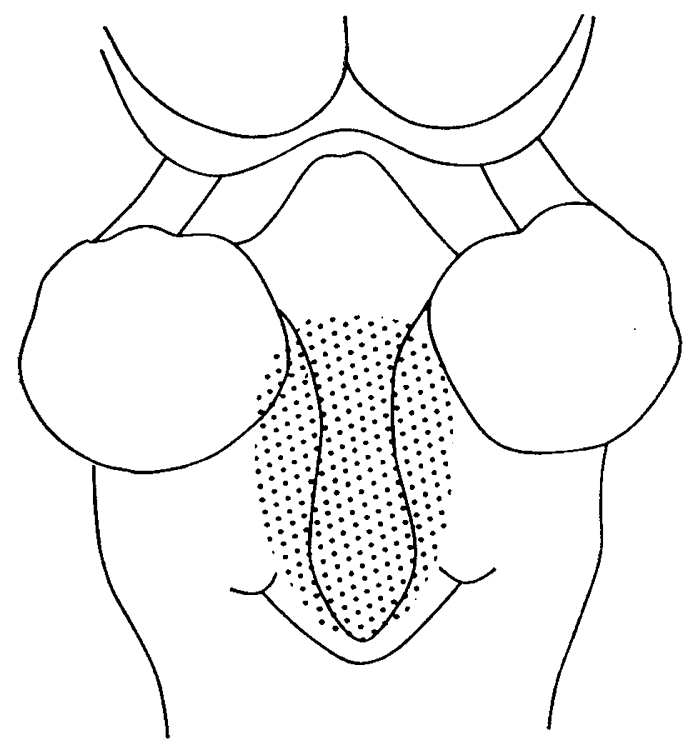

Fig. 3. Horizontal projection onto the dorsal surface of the fetal medulla indicating the area from which a ventilatory response was obtained.

tion of the medulla. The numbers of placements in each coronal plane and the incidence of responses to increasing stimulating currents are summarized in Table II.
The response to stimulation of the brain stem of the neonatal lambs was remarkably different than that of the fetal animals. Spontaneous rhythmic respiration was present in these animals. Increasing the stimulating current resulted in a progressive diminution of tidal volume and an increase in respiratory rate until a current was reached which produced an apneic pause (Figs. 4 and 5). This apneic pause occurred at about the same current required to initiate a respiratory response in the fetus. It was always possible to induce an apneic pause if there had been a depression of tidal

Table II. Occurrences of sites with low, middle, and high thresholds in different regions of medulla oblongata ${ }^{1}$

\begin{tabular}{|c|c|c|c|c|c|}
\hline \multirow{3}{*}{ Coronal section } & \multicolumn{5}{|c|}{ Threshold in fetus } \\
\hline & \multicolumn{3}{|c|}{$\mathrm{ma}$} & \multirow{2}{*}{$\begin{array}{l}\text { No re- } \\
\text { sponse to } \\
1.5 \mathrm{ma}\end{array}$} & \multirow{2}{*}{$\begin{array}{c}\text { Total } \\
\text { number of } \\
\text { placements }\end{array}$} \\
\hline & $<0.6$ & $0.6-1.0$ & $1.0-1.5$ & & \\
\hline Section $1,0 \mathrm{~mm}$ & $\begin{array}{c}3 \\
(5.8)\end{array}$ & $\begin{array}{c}3 \\
(5.8)\end{array}$ & $\begin{array}{c}5 \\
(9.6)\end{array}$ & $\begin{array}{c}41 \\
(78.8)\end{array}$ & $\begin{array}{c}52 \\
(100)\end{array}$ \\
\hline$\underset{\text { mm }}{\text { Section } 2,+3}$ & $\begin{array}{c}15 \\
(12.3)\end{array}$ & $\begin{array}{c}18 \\
(14.7)\end{array}$ & $\begin{array}{c}20 \\
(16.4)\end{array}$ & $\begin{array}{c}69 \\
(56.6)\end{array}$ & $\begin{array}{c}122 \\
(100)\end{array}$ \\
\hline$\underset{\text { Section } 3,+6}{\text { mm }}$ & $\begin{array}{c}14 \\
(13.5)\end{array}$ & $\begin{array}{c}26 \\
(25.0)\end{array}$ & $\begin{array}{c}14 \\
(13.5)\end{array}$ & $\begin{array}{c}50 \\
(48.1)\end{array}$ & $\begin{array}{c}104 \\
(100)\end{array}$ \\
\hline$\underset{\mathrm{mm}}{\text { Section } 4 .+9}$ & $\begin{array}{c}4 \\
(8.5)\end{array}$ & $\begin{array}{c}10 \\
(21.3)\end{array}$ & $\begin{array}{c}9 \\
(19.2)\end{array}$ & $\begin{array}{c}24 \\
(51.1)\end{array}$ & $\begin{array}{c}47 \\
(100)\end{array}$ \\
\hline
\end{tabular}

1 Coronal sections correspond to those in Figure 2. Percentages appear in paren. theses. 


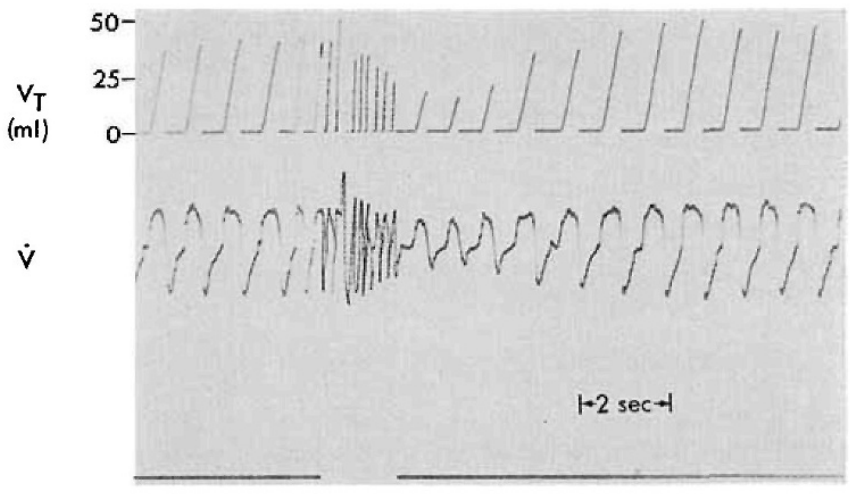

Fig. 4. Recording illustrating effect of subthreshold stimulation of medulla from neonatal lambs. Integrated inspired tidal volume and flow are displayed from top to bottom. The onset and withdrawal of the stimulating current is indicated by the marker channel. Note the increase in respiratory rate and diminution of tidal volume associated with subthreshold stimulation.

volume at low current strengths. The location of the area from which apneic responses were obtained is shown in coronal sections through the brain stem in Figure 6 and on a horizontal projection onto the dorsal surface of the medulla in Figure 7. The number of placements in each coronal plane and the incidence of apneic responses at increasing stimulating currents is summarized in Table III. The maximum response was obtained in an area about $3 \mathrm{~mm}$ rostral to the obex, extending laterally for a maximum of about $2 \mathrm{~mm}$ on either side of the midline. This area was much more localized than the area in the fetal lamb, being con-

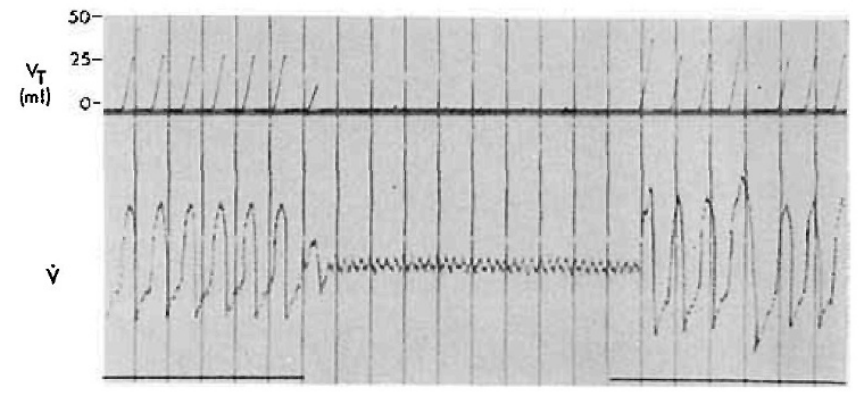

Fig. 5. Recording of integrated inspired tidal volume and flow illustrating effect of threshold stimulation of medulla from neonatal lambs. Onset and withdrawal of stimulus indicated by marker channel. Note apnea within $1 \mathrm{sec}$ after application of stimulus and return of spontaneous respiration I sec after withdrawal of stimulus. Time lines indicate seconds.
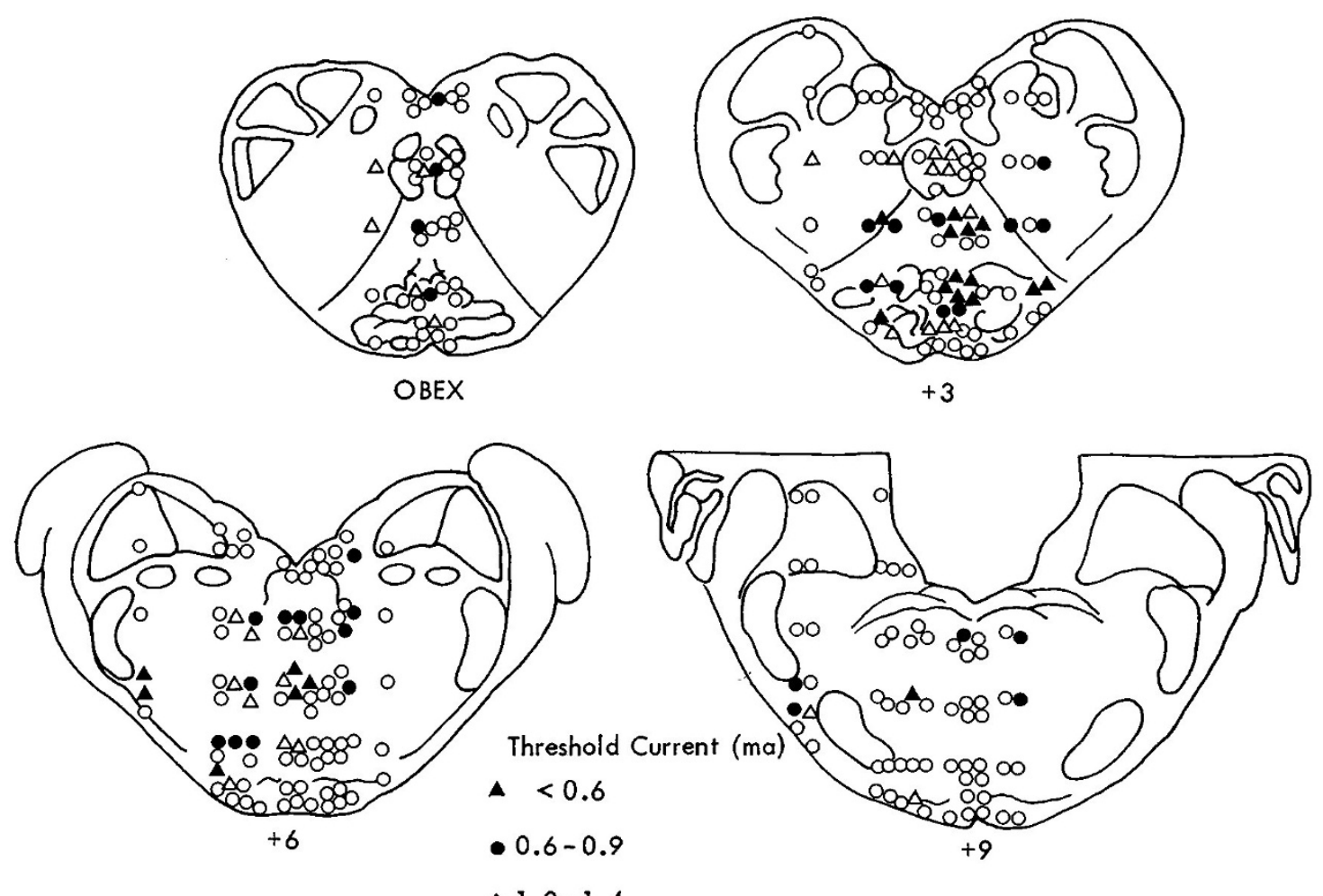

$\Delta 1.0-1.4$

O NO RESPONSE TO 1.5

Fig. 6. Representative coronal sections of the brain stem of neonatal lambs at levels comparable to those shown in Figure 1. Symbols indicating sites of response and the threshold voltage similar to those used in the latter figure. —-: $4 \mathrm{~mm}$. 
fined almost entirely to the ventral portion of the medulla, near the obex. The area of respiratory response in the neonatal sheep was very similar to that of the adult sheep described previously $[1,2]$.

\section{Discussion}

Focal stimulation of the brain stem to localize the medullary respiratory structures has been utilized in several adult animal species $[1,5-7,9-11]$. Previous studies in fetal animals have been indirect. Barcroft [3], studying the exteriorized fetal sheep, observed that respiratory responses were elicited in early fetal life by tactile stimulation of the area supplied by the trigeminal nerve. However, there was no response after 60 days gestation (term is 148 days) and he concluded that the respiratory center was present early in fetal life but inhibited by some central mechanism near term. Barcroft sectioned the brain at various levels and concluded that there was active inhibition of the medullary respiratory center by higher centers rostral to the pons.

The present experiments were designed to compare the medullary respiratory structures of fetal sheep near term neonatal lambs. Stereotaxic placement of the stimulating electrode allowed precise anatomic localization as has been previously described for adult animals.

In the neonatal lambs we used a more modified definition of what constitutes a ventilatory response than has been previously used [1]. Since ventilation was monitored by a pneumotachograph with an integrated tidal volume, inspiratory or expiratory shifts in lung volumes were not recorded. However, visual inspection revealed that the vast majority of the responses were inspiratory. Recorded responses consisted of a diminution of the tidal volume and, with an increasing current, an apneic pause. Using this definition of a response the respiratory area mapped in the neonatal lamb was similar in location to that described for the inspiratory center of the adult sheep, particularly the lowest threshold responses which occurred more ventrally in the medulla. Thus, we did not define a separate expiratory area. The volume of the respiratory center in the medulla of the neonatal lamb was about $65 \mathrm{~mm}^{3}$ and similar to that which we calculated from the published data on adult sheep [1].

In contrast to the neonatal lamb, tidal volume was measured directly in the fetal sheep. It is of interest that, with the exception of one or two instances, all responses were inspiratory. The rare expiratory response of a very small volume seemed to be nonspe- cific, inasmuch as it was associated with a generalized muscular contraction. Furthermore, the region from which responses could be obtained was more diffuse than in neonatal or adult sheep and occupied a volume about double that calculated for neonatal and adult sheep. This response appeared to be specific and not caused by an increased spread of current, inasmuch as nonresponsive areas were found within 1-2 $\mathrm{mm}$ of the sites at which stimulation resulted in a prompt inspiration.

The similarity of the thresholds for the initiation of respiration in the fetus and the induction of apnea in the neonatal animal is striking. However the validity of such a comparison of the threshold currents required for a response between fetal and neonatal sheep must be examined critically. The validity of this comparison is supported by the following observation. On rare occasion an exteriorized fetus will begin spontaneous, rhythmic respiration which is maintained for

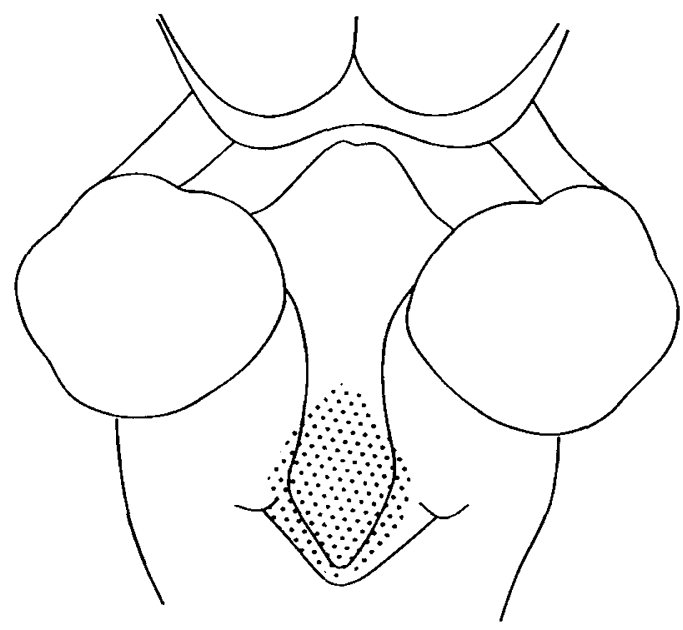

Fig. 7. Horizontal projection onto the dorsal surface of medulla of neonatal lambs indicating the arca of ventilatory response to the stimulating current.

Table III. Occurrences of sites with low, middle, and high thresholds in different regions of medulla oblongata ${ }^{1}$

\begin{tabular}{|c|c|c|c|c|c|}
\hline \multirow{3}{*}{$\begin{array}{l}\text { Coronal } \\
\text { plane, } \\
\text { distance } \\
\text { from obex, } \\
\text { mm }\end{array}$} & \multicolumn{5}{|c|}{ Threshold in neonatal lambs } \\
\hline & \multicolumn{3}{|c|}{$\mathrm{ma}$} & \multirow{2}{*}{$\begin{array}{l}\text { No re- } \\
\text { sponse to } \\
1.5 \mathrm{ma}\end{array}$} & \multirow{2}{*}{$\begin{array}{c}\text { Total } \\
\text { number of } \\
\text { placements }\end{array}$} \\
\hline & $<0.6$ & $0.6-1.0$ & $1.0-1.5$ & & \\
\hline Section $1,0 \mathrm{~mm}$ & $\begin{array}{c}0 \\
(0.0)\end{array}$ & $\begin{array}{c}4 \\
(10.0)\end{array}$ & $\begin{array}{c}5 \\
(12.5)\end{array}$ & $\begin{array}{c}31 \\
(77.5)\end{array}$ & $\begin{array}{c}40 \\
(100)\end{array}$ \\
\hline $\begin{array}{l}\text { Section } 2,+3 \\
\mathrm{~mm}\end{array}$ & $\begin{array}{c}13 \\
(14.9)\end{array}$ & $\begin{array}{c}10 \\
(11.5)\end{array}$ & $\begin{array}{c}13 \\
(14.9)\end{array}$ & $\begin{array}{c}51 \\
(58.6)\end{array}$ & $\begin{array}{c}87 \\
(100)\end{array}$ \\
\hline $\begin{array}{l}\text { Section } 3 .+6 \\
\mathrm{~mm}\end{array}$ & $\begin{array}{c}6 \\
(6.6)\end{array}$ & $\begin{array}{c}10 \\
(11.0)\end{array}$ & $\begin{array}{c}8 \\
(8.8)\end{array}$ & $\begin{array}{c}67 \\
(73.6)\end{array}$ & $\begin{array}{c}91 \\
(100)\end{array}$ \\
\hline $\begin{array}{l}\text { Section } 4 .+9 \\
\mathrm{~mm}\end{array}$ & $\begin{array}{c}1 \\
(1.6)\end{array}$ & $\begin{array}{c}5 \\
(7.8)\end{array}$ & $\begin{array}{c}2 \\
(3.2)\end{array}$ & $\begin{array}{c}56 \\
(87.5)\end{array}$ & $\begin{array}{c}64 \\
(100)\end{array}$ \\
\hline
\end{tabular}

${ }_{1}^{1}$ Coronal sections correspond to those in Figure 6. Percentages appear in parentheses. 
up to an hour, despite the presence of normal fetal blood gas tensions. In one such fetal animal we were able to produce an apneic pause by stimulating the medulla. Later, spontaneous respiration ceased and stimulation of the medulla in the same location and with the same current was associated with several inspiratory gasps. Thus, the nature of the respiratory response to electrical stimulation of the brain stem within the same fetus depended on the presence or absence of rhythmic respiration.

Recent observations indicate that the fetus in utero is not totally apneic but does have spontaneous rhythmic respiration about $40 \%$ of the time [8]. This is in contrast to our observations that the exteriorized anesthetized fetal sheep rarely has spontaneous ventilation. The low current required for a respiratory response suggests that any inhibition produced by anesthesia and exteriorization can be overcome easily but persists, inasmuch as removal of the stimulating current is followed by apnea. Stimulation of the brain stem in the manner used in the present experiments is artificial and does not necessarily simulate the neurophysiological organization of respiratory control mechanisms. It is therefore difficult to speculate further from the present data on the functional organization of the fetal respiratory center and further investigation of the exteriorized and in situ fetus is required.

\section{Summary}

The functional organization of medullary respiratory neurones during fetal life must be complete as term approaches in preparation for extrauterine life. Direct study of the fetal respiratory center has not been previously undertaken. Focal electrical stimulation of the medulla of anesthetized, exteriorized fetal sheep was undertaken and the area from which respiratory responses were obtained was mapped using stereotaxic coordinates. Ventilation was monitored by connecting the cannulated trachea to a liquid plethysmograph. The area in the brain stem from which respiratory responses were elicited was diffuse and extended from obex to lower pons. The region occupied a volume of about $130 \mathrm{~mm}^{3}$. The exteriorized fetus is usually apneic and focal stimulation resulted in one or two inspiratory gasps. In one exteriorized fetus with spontaneous rhythmic ventilation, focal medullary stimulation caused an apneic pause. Later, when respiration ceased spontaneously, focal stimulation at the same current strength induced inspiratory gasps. In the neo- natal lamb breathing spontaneously, focal stimulation of the medulla was associated with a diminution in tidal volume and an apneic pause could be produced with an increase in current strength. The apneic pause occurred at a current strength similar to that required to initiate respiration in the fetus. In the neonatal lamb the area in the brain stem from which a respiratory response could be obtained was less diffuse than that of the fetus and occupied a volume of about 65 $\mathrm{mm}^{3}$. These data indicate a significant difference in ventilatory response to electrical stimulation of the brain stem in the apneic and breathing sheep. It is suggested that the ventilatory response is dependent on the functional state of the respiratory neurones.

\section{References and Notes}

1. Amoroso, E. C., Bell, F. R., And Rosenberg, H.: The localization of respiratory regions in the rhombencephalon of the sheep. Proc. Royal Soc. London, 138: 128 (1951).

2. Amoroso, E. C., Bell, F. R., and Rosenberg, H.: The relationship of the vasomotor and respiratory regions in the medulla oblongata of the sheep. J. Physiol., 126: 86 (1954).

3. Barcroft, J.: Researches on Pre-Natal Life, pp. 30, 260. (Blackwell, Oxford, 1946).

4. Burns, B. D., and Salmoiraghr, G. C.: Repetitive firing of respiratory neurones during their burst activity. J. Neurophysiol., 23: 27 (1960).

5. BRookhart, J. M.: The respiratory effects of localized faradic stimulation of the medulla oblongata. Amer. J. Physiol., 129: 709 (1940).

6. Carregal, E. J. A., Williams, B., And Birzis, L.: Respiratory centers in the dog and squirrel monkey: a comparison study. Resp. Physiol., 3: 333 (1967).

7. Comroe, J. H.: The effects of direct chemical and electrical stimulation of the respiratory center in the cat. Amer. J. Physiol., 139: 490 (1943).

8. Dawes, G. S., Fox, H. E., Leduck, B. M., Liggins, G. C., ANd RichaRDS, R. T.: Respiratory movements and rapid eye movement sleep in the foetal lamb. J. Physiol., 220: 119 (1972).

9. Magoun, H. W., and Beaton, L. E.: Respiratory responses from stimulation of the medulla of the cat. Amer. J. Physiol., 134: $186(1941)$.

10. Oberholzer, J. H., and Tofani, W. O.: The neural control of respiration. In: J. Field: Handbook of Physiology, Section 1, Neurophysiology, Vol. 11. The Williams and Wilkins Co., Baltimore, 1960).

11. WANG, S. C., AND NGar, S. H.: General Organization of Central Respiratory Mechanisms. In: W. O. Fen and H. Rahn: Handbook of Physiology, Section 3, Respiration, Ed. 2, Vol. 1. (The Williams and Wilkins Co., Baltimore, 1964).

12. Grass $\mathrm{S} 8$ stimulator, Grass Instrument Co., Quincy, Mass.

13. Electronics for Medicine recorder, Electronics for Medicine, White Plains, N. Y. 
14. We gratefully acknowledge the critical review of this manuscript by Dr. J. W. Phillis and Dr. C. Pinsky, and the expert technical assistance of Mr. B. Russell.

15. Dr. V. Chernick is a Queen Elizabeth II Scientist.

16. The present address of Dr. A. Sklenovsky is: Department of Pathologic Physiology, Palacky University, Faculty of Medicine, Olomouc, Czechoslovakia.
17. This research was supported by the Medical Research Council of Canada and the Children's Hospital Research Foundation.

18. Requests for reprints should be addressed to: V. Chernick, M.D., Children's Hospital, Winnipeg, Manitoba, R3E OW1 (Canada).

19. Accepted for publication September 20, 1972. 